\title{
Synthesis of carbon nanotube peapods directly on Si substrates
}

Y. Ohno, ${ }^{\text {a),b) }}$ Y. Kurokawa, S. Kishimoto, and T. Mizutani

Department of Quantum Engineering, Nagoya University, Furo-cho, Chikusa-ku, Nagoya 464-8603, Japan

T. Shimada, M. Ishida, T. Okazaki, and H. Shinohara ${ }^{\text {() }}$

Department of Chemistry, Nagoya University, Furo-cho, Chikusa-ku, Nagoya 464-8602, Japan

Y. Murakami and S. Maruyama

Department of Mechanical Engineering, The University of Tokyo, 7-3-1 Hongo, Bunkyo-ku, Tokyo 113-8656, Japan

A. Sakai

Department of Crystalline Materials Science, Nagoya University, Furo-cho, Chikusa-ku, Nagoya 464-8603, Japan

K. Hiraga

Institute for Materials Research, Tohoku University, Sendai 980-8577, Japan

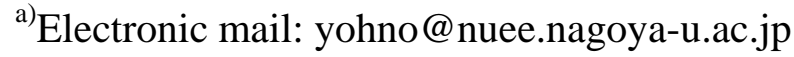

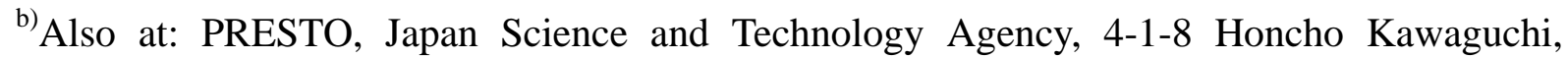
Saitama 332-0012, Japan

${ }^{c}$ Also at: CREST, Japan Science and Technology Agency, 4-1-8 Honcho Kawaguchi, Saitama 332-0012, Japan 


\begin{abstract}
Carbon nanotubes encapsulating fullerenes, peapods, have been synthesized directly on Si substrates. High-density and high-quality singe-walled carbon nanotubes (SWNTs) were grown on a $\mathrm{SiO}_{2} / \mathrm{Si}$ substrate by dip-coating of metal acetate solution and alcohol chemical vapor deposition technique. The caps of SWNTs were opened by annealing in dry air. Then, fullerene doping into the SWNTs was performed by vapor phase doping technique. Encapsulations of $\mathrm{C}_{60}$ and $\mathrm{Gd} @ \mathrm{C}_{82}$ were confirmed by transmission electron microscopy. Raman scattering spectroscopy was performed for synthesized peapods. From Raman scattering spectroscopy of synthesized peapods, the smallest diameters of the SWNTs capable of fullerene encapsulation were estimated to be $1.28 \mathrm{~nm}$ for $\mathrm{C}_{60}$ and $1.43 \mathrm{~nm}$ for $\mathrm{Gd} @ \mathrm{C}_{82}$.
\end{abstract}


Single-walled carbon nanotubes (SWNTs) encapsulating fullerenes, so-called 'peapods', are attracting materials for electronics applications because of the interesting electronic property. It has been predicted from the calculations using the local-density approximation that the band structure of a SWNT is modulated by encapsulating fullerenes. ${ }^{2} \mathrm{~J}$. Lee et al. have shown the local bandgap modulation in $\mathrm{Gd} @ \mathrm{C}_{82}$ peapod due to the existence of $\mathrm{Gd} @ \mathrm{C}_{82}$ fullerenes by scanning tunneling spectroscopy. ${ }^{3}$ Recently, we have reported fabrication and characterization of FETs of various types of peapods encapsulated with such fullerenes as $\mathrm{C}_{60}, \mathrm{C}_{90}$, and metallofullerenes as $\mathrm{Gd}_{\mathrm{a}} \mathrm{C}_{82}$, Dy@ $\mathrm{C}_{82}$ and so on. ${ }^{4,5}$ The devices showed ambipolar characteristics, and the gate voltage width of the off-state region of the transfer characteristics was varied with the kinds of encapsulated fullerenes. The results suggest that it is possible to control the energy gap by choosing the metallofullerenes because the off-state width of the gate voltage has close correlation with the bandgap. These characteristics, so-called bandgap engineering, is expected to open new horizons to the electronics device engineers.

In the previous studies on peapod FETs, the devices were fabricated by dropping peapods on $\mathrm{SiO}_{2} / \mathrm{Si}$ substrate with electrodes. In this method, peapods were obtained as soot, dispersed in organic chemical solution, and then dropped on a $\mathrm{SiO}_{2} / \mathrm{Si}$ substrate with electrodes. In this case, the yield of peapod FETs was quite low. In order to characterize peapod FETs in detail and to apply them to nano-electronics, it is important to develop a reliable fabrication process, in which the peapods are synthesized directly on a substrate similar to SWNT FETs. ${ }^{6,7}$

In this letter, we have successfully synthesized $\mathrm{C}_{60}$ peapods and $\mathrm{Gd} @ \mathrm{C}_{82}$ peapods directly on $\mathrm{SiO}_{2} / \mathrm{Si}$ substrates. The proposed procedure for the synthesis of peapods is as follows; 1) catalytic metal deposition on a $\mathrm{SiO}_{2} / \mathrm{Si}$ substrate, 2) thermal chemical vapor deposition (CVD) of pod SWNTs, 3) cap opening of the pod SWNTs by annealing in dry air, 
and 4) doping of pea fullerenes in vapor phase. Transmission electron microscopy (TEM) and Raman scattering spectroscopy were performed to characterize the synthesized peapods.

In the present work, in order to obtain sufficient amount of peapods for the characterizations such as TEM observation and Raman scattering, we employed the dip-coating method for catalytic metal deposition on the substrate and the alcohol catalytic CVD for the synthesis of pod SWNTs. ${ }^{8}$ A metal acetate solution was prepared by dissolving molybdenum acetate $\left(\mathrm{CH}_{3} \mathrm{COOH}\right)_{2} \mathrm{Mo}$ and cobalt acetate $\left(\mathrm{CH}_{3} \mathrm{COOH}\right)_{2} \mathrm{Co} \cdot 4 \mathrm{H}_{2} \mathrm{O}$ into ethanol so that the concentration of each metallic species was $0.01 \mathrm{wt} \%$. The mixture of ethanol and $\mathrm{H}_{2}$ was used as the source gas for the CVD. The growth temperature, time, and total pressure in the CVD furnace were $800^{\circ} \mathrm{C}, 10 \mathrm{~min}$, and 20 torr, respectively. The details have been described in Ref. 8.

Figure 1 shows the Raman scattering spectrum of synthesized SWNTs. An SEM image of the sample is also shown in the inset. High-density bundles of SWNTs were synthesized on the substrate. For the Raman measurement, the excitation wavelength was 515 $\mathrm{nm}$ of $\mathrm{Ar}^{+}$laser. The scattered light was dispersed by a 1-m double monochromator and detected by a liquid-nitrogen-cooled charge-coupled device. The large G-band/D-band-intensity ratio (G/D ratio) of the Raman scattering spectrum suggests that synthesized SWNTs are of high quality. The combination of the dip-coating of catalysts and the alcohol CVD yielded high-density and high-quality $\mathrm{SWNTs}$ on the $\mathrm{SiO}_{2} / \mathrm{Si}$ substrate.

In the conventional method to synthesize peapods, the end caps of pod SWNTs were opened by the purification process using $\mathrm{H}_{2} \mathrm{O}_{2}$ reflux and subsequent $\mathrm{HCl}$ oxidation. ${ }^{4,9,10}$ In the present sample, these process would remove SWNTs away from the substrates. Therefore, we have employed the method in which the cap opening was performed by annealing in a mixture of $\mathrm{N}_{2} / \mathrm{O}_{2}(4 / 1)$ for $30 \mathrm{~min}$. The caps of $\mathrm{SWNTs}$ have pentagonal rings which are easily oxidized compared with hexagonal rings of graphen sheet. Then, only caps of SWNTs 
would be eliminated without any damages in the nanotube wall. The condition of the cap opening was determined by Raman scattering spectroscopy measurement. The G-band intensity and G/D ratio, which are indices of the amount and the quality of SWNTs respectably, are summarized in Fig. 2 as a function of annealing temperature of the cap-opening process. The changes in the G-band intensity and the G/D ratio were small after annealing at temperatures below $470^{\circ} \mathrm{C}$, whereas significant decrease in them was observed after annealing at temperatures above $500^{\circ} \mathrm{C}$. The annealing below $470^{\circ} \mathrm{C}$ did not cause any detectable damages in the SWNTs. These results agree with that of thermo-gravimetric analysis. $^{11}$

The insertion of fullerenes into the cap-opened SWNTs was carried out by vapor phase method..$^{9,10}$ The substrate with the SWNTs was put into a sealed glass ampoule with fullerenes, and then heated at $500^{\circ} \mathrm{C}$ for 2 days. Figure 3 shows TEM images of synthesized (a) $\mathrm{C}_{60}$ peapods and (b) $\mathrm{Gd} @ \mathrm{C}_{82}$ peapods. In both samples, one-dimensional arrays of fullerenes were observed. The encapsulation of fullerenes into SWNTs was confirmed by TEM for the samples annealed at temperatures above $450^{\circ} \mathrm{C}$.

Raman scattering spectroscopy was performed for the peapods synthesized on a $\mathrm{SiO}_{2} / \mathrm{Si}$ substrate. Here, the samples were mounted on a copper finger of a cryostat and cooled at $80 \mathrm{~K}$ in order to prevent polymerization of encapsulated fullerenes due to the laser irradiation. ${ }^{9}$ Figure 4 shows Raman spectra of radial breathing modes (RBM) for as-synthesized SWNTs, $\mathrm{C}_{60}$ peapods, and $\mathrm{Gd} @ \mathrm{C}_{82}$ peapods for two excitation wavelengths of $515 \mathrm{~nm}$ (lower curves) and $740 \mathrm{~nm}$ (upper curves). The vertical dotted lines in the figure indicate the Raman frequencies of RBM peaks of as-synthesized SWNTs. Since the present CVD sample contains various SWNTs with different diameters, several RBM peaks were observed from 160 to $280 \mathrm{~cm}^{-1}$. Some RBM peaks of $\mathrm{C}_{60}$ and $\mathrm{Gd} @ \mathrm{C}_{82}$ peapods shifted to lower frequency compared to those of SWNTs in the low frequency region, whereas the peaks 
in the high frequency region did not shift by the fullerene doping. The down shift of RBM peaks caused by encapsulation of fullerenes are thought to be caused by an increase in diameter of pod SWNT or a change of the inter-tube interaction. ${ }^{12}$ Therefore, the observation of the down shift of RBM peaks suggests the encapsulation of fullerenes into the SWNTs. The high-frequency peaks which did not shift probably correspond to empty SWNTs because of the small diameter.

To show clearly the small shift of RBM peaks, the amount of shifts is plotted in Fig. 5 as a function of the diameter of as-synthesized SWNTs. Here, we assumed that the diameter of a SWNT $(d)$ is given by the Raman frequency of the RBM $\left(\omega_{\mathrm{RBM}}\right)$ as $d=248 / \omega_{\mathrm{RBM}} \cdot{ }^{13}$ The shift of RBM peaks was observed for the diameter larger than $d=1.28 \mathrm{~nm}$ for $\mathrm{C}_{60}$ peapods and $d=1.43 \mathrm{~nm}$ for $\mathrm{Gd} @ \mathrm{C}_{82}$ peapods. These values of $d$ probably represent the smallest diameters of pod SWNTs for the fullerene encapsulation. The smallest diameters of pod SWNTs for the fullerene encapsulation were slightly larger than the diameter of pea fullerenes, $0.71 \mathrm{~nm}$ for $\mathrm{C}_{60}$ and $0.83 \mathrm{~nm}$ for $\mathrm{Gd} @ \mathrm{C}_{82}$. According to the theoretical study on reaction energy for $\mathrm{C}_{60}$ encapsulation by S. Okada et al., the smallest diameter of the SWNT which is capable of encapsulating $\mathrm{C}_{60}$ is about $1.28 \mathrm{~nm}^{2}$ The present results agree with the theoretical prediction.

In summary, $\mathrm{C}_{60}$ and $\mathrm{Gd} @ \mathrm{C}_{82}$ peapods have been successfully synthesized directly on $\mathrm{SiO}_{2} / \mathrm{Si}$ substrates. High-density and high-quality $\mathrm{SWNTs}$ were grown on a $\mathrm{SiO}_{2} / \mathrm{Si}$ substrate by dip-coating of catalysts and alcohol catalytic CVD. The caps of SWNTs were opened by annealing in dry air at $450 \sim 470^{\circ} \mathrm{C}$ without any detectable damages in Raman measurement. Fullerene doping into the SWNTs was performed by vapor phase doping technique. Encapsulations of $\mathrm{C}_{60}$ and $\mathrm{Gd} @ \mathrm{C}_{82}$ were confirmed using transmission electron microscopy. A down shift of the RBM peaks of Raman scattering spectra was caused by the fullerene doping. The smallest diameters of the SWNTs capable of fullerene encapsulation 
were estimated from the existence of the down shifts to be $1.28 \mathrm{~nm}$ for $\mathrm{C}_{60}$ and $1.43 \mathrm{~nm}$ for $\mathrm{Gd} @ \mathrm{C}_{82}$.

Acknowledgment

This work was supported in part by the Special Coordination Funds of the Ministry of Education, Culture, Sports, Science, and Technology of the Japanese Government. 


\section{References}

${ }^{1}$ B. W. Smith, M. Monthioux, and D. E. Luzzi, Nature 396, 323 (1998).

${ }^{2}$ S. Okada, S. Saito, and A. Oshiyama, Phys. Lev. Lett. 86, 3835 (2001).

${ }^{3}$ J. Lee, H. Kim, S.-J. Kahng, G. Kim, Y.-W. Son, J. Ihm, H. Kato, Z. W. Wang, T. Okazaki, H. Shinohara, and Y. Kuk, Nature 415, 1005 (200).

${ }^{4}$ T. Shimada, T. Okazaki, R. Taniguchi, T. Sugai, H. Shinohara, K. Suenaga, Y. Ohno, S. Mizuno, S. Kishimoto, and T. Mizutani, Appl. Phys. Lett. 81, 4067 (2002).

${ }^{5}$ T. Shimada, Y. Ohno, T. Okazaki, T. Sugai, K. Suenaga, S. Iwatsuki, S. Kishimoto, T. Mizutani, T. Inoue, R. Taniguchi, N. Fukui, H. Okubo, and H. Shinohara, Physica E 21, 1089 (2004).

${ }^{6}$ H. T. Soh, C. F. Quate, A. F. Morpurgo, C. M. Marcus, J. Kong, and H. Dai, Appl. Phys. Lett. 75, 627 (1999).

${ }^{7}$ Y. Ohno, S. Iwatsuki, T. Hiraoka, T. Okazaki, S. Kishimoto, K. Maezawa, H. Shinohara, and T. Mizutani, Jpn. J. Appl. Phys. Part 1 42, 4116 (2003).

${ }^{8}$ Y. Murakami, Y. Miyauchi, S. Chiashi, and S. Maruyama, Chem. Phys. Lett. 377, 49 (2003).

${ }^{9}$ H. Katarura, Y. Maniwa, T. Kodama, K. Kikuchi, K. Hirahara, K. Suenaga, S. Iijima, S. Suzuki, Y. Achiba, and W. Kratschmer, Synt. Met. 121, 1195 (2001).

${ }^{10}$ K. Hirahara, K. Suenaga, S. Bandow, H. Kato, T. Okazaki, H. Shinohara, and S. Iijima, Phys. Rev. Lett. 85, 5384 (2000).

${ }^{11}$ Y. Murakami, Y. Miyauchi, S. Chiashi, and S. Maruyama, Chem. Phys. Lett. 374, 53 (2003).

${ }^{12}$ R. Pfeiffer, H. Kuzmany, W. Plank, T. Pichler, H. Kataura, and Y. Achiba, Diamond Relat. Mater. 11, 957 (2002).

${ }^{13}$ A. Jorio, R. Saito, J.H. Hafner, C.M. Lieber, dM. Hunter, T. McClure, G. Dresselhaus, M.S. Dresselhaus, Phys. Rev. Lett. 861118 (2001). 
Figure captions

Fig. 1 Raman scattering spectrum and SEM image (inset) of SWNTs synthesized on $\mathrm{SiO}_{2} / \mathrm{Si}$ substrate.

Fig. 2 (a) Intensity of G-band and (b) intensity ratio of G-band and D-band of Raman scattering spectra as a function of anneal temperature.

Fig. 3 TEM images of synthesized peapods, (a) $\mathrm{C}_{60}$ peapods and (b) $\mathrm{Gd} @ \mathrm{C}_{82}$ peapods.

Fig. 4 Radial breathing mode of synthesized SWNTs, $\mathrm{C}_{60}$ peapods, and $\mathrm{Gd} @ \mathrm{C}_{82}$ peapods.

Fig. 5 Shift of RBM peaks caused by encapsulating fullerenes as a function of the diameter of pod SWNT. 


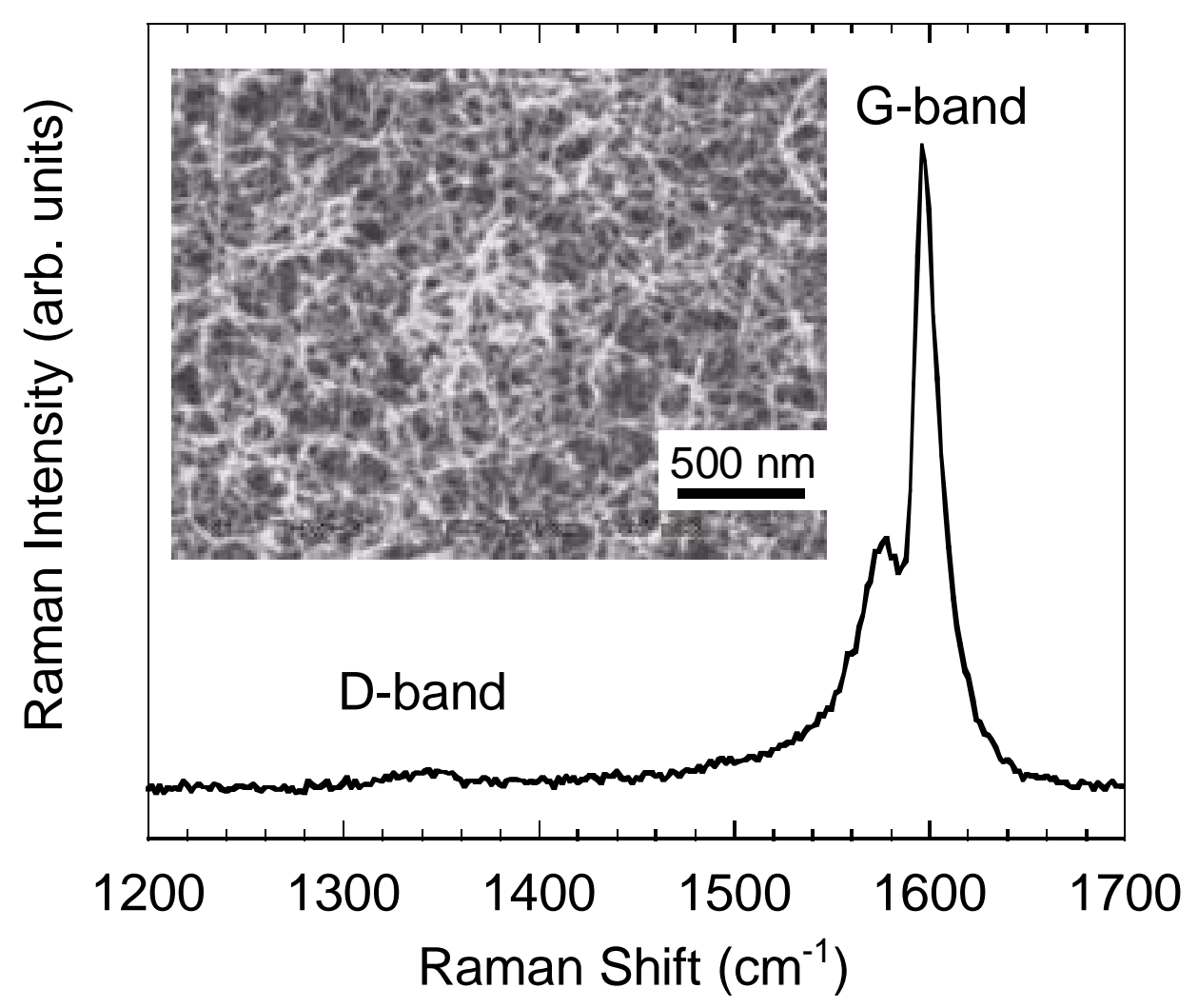

Fig. 1

Y. Ohno 


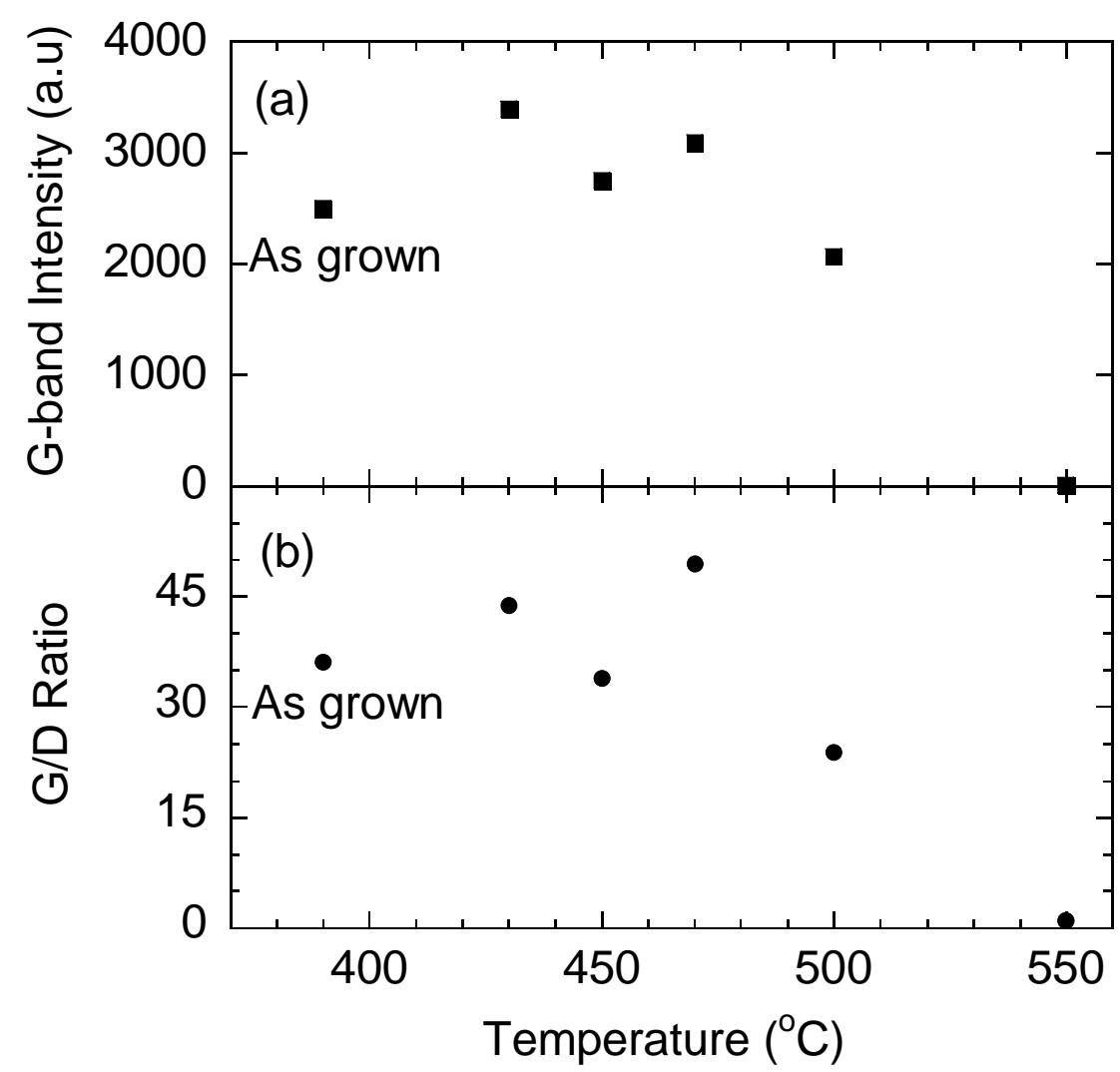

Fig. 2

Y. Ohno 

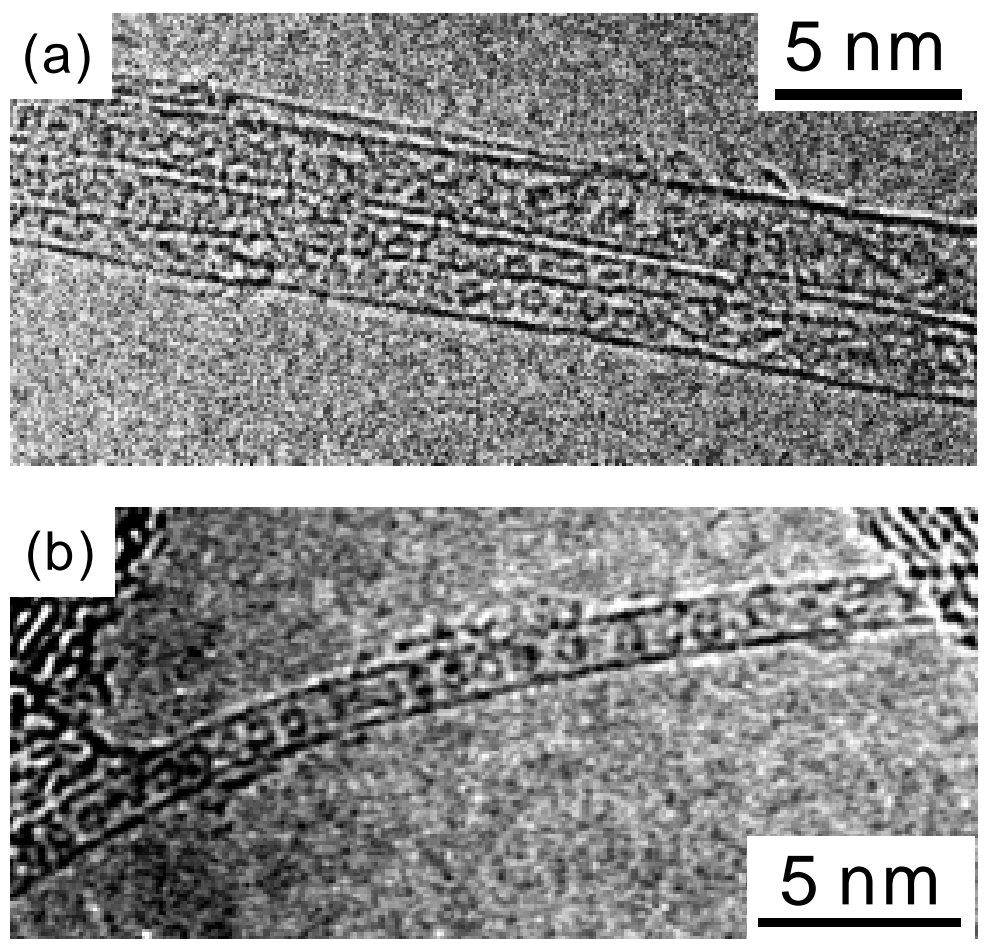

Fig. 3

Y. Ohno 


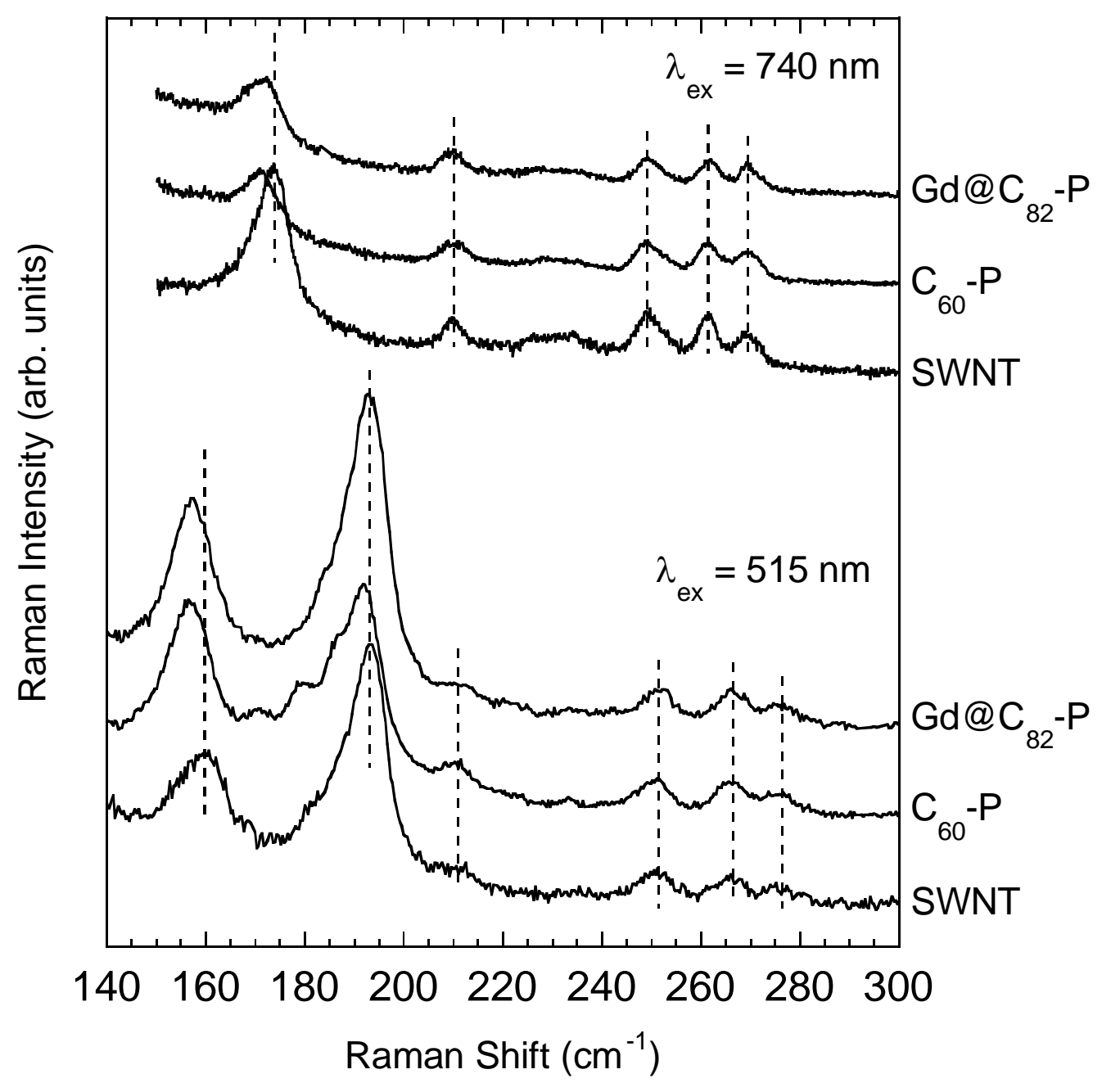

Fig. 4

Y. Ohno 


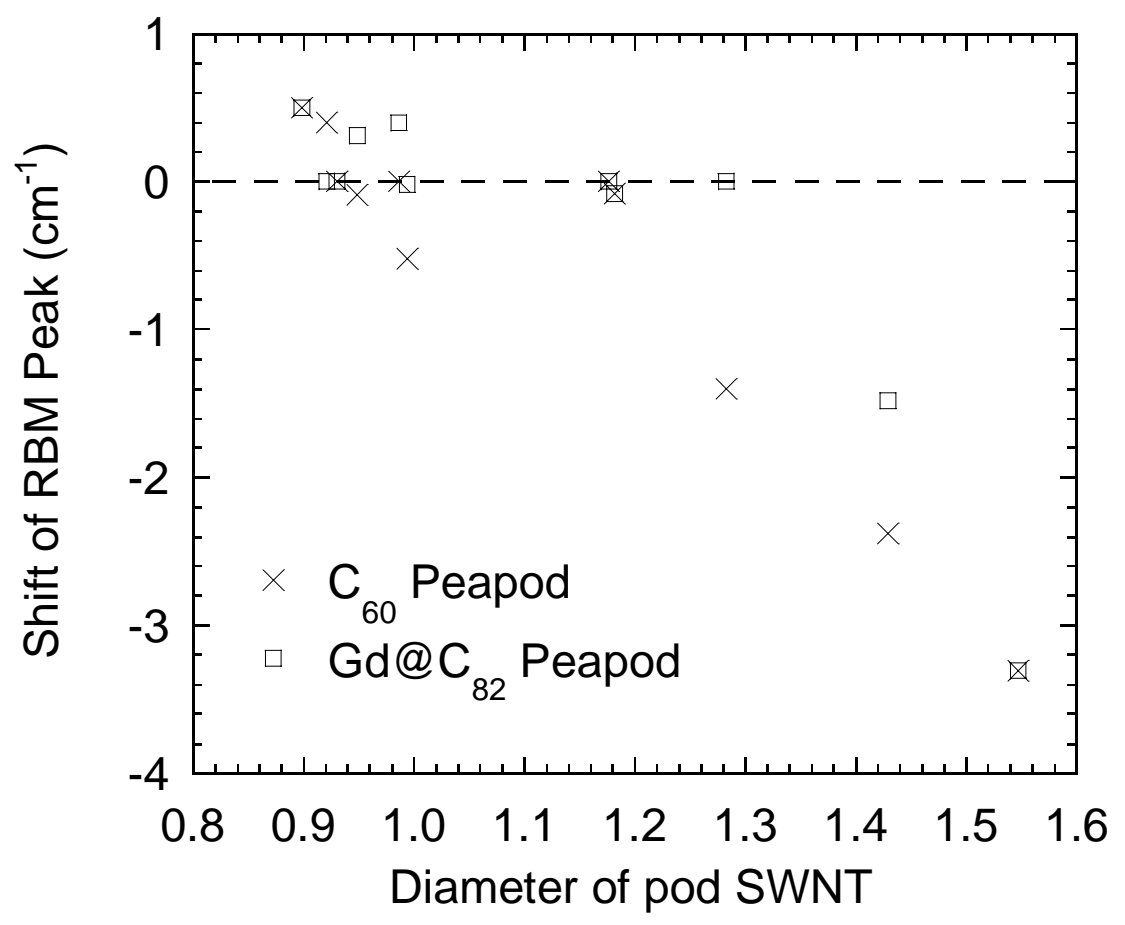

Fig. 5
Y. Ohno 